\title{
Camtasia Studio Learning Video For Mathematical Literature Levels Students
}

\author{
Laelasari $^{1,2, a}$, Riskha Arfiyanti ${ }^{1,2, b}$, Mira Nuryanti ${ }^{1,3, c}$, Sri Adi Widodo ${ }^{4, d}$, Tri Astuti Arigiyati ${ }^{4, e}$ \\ lala.mathunswagati@gmail.com ${ }^{\mathrm{a}}$, arfiyanti.riskha@gmail.com ${ }^{\mathrm{b}}$, miranuryanti@yahoo.co.id ${ }^{\mathrm{c}}$, \\ sriadi@ustjogja.ac.id ${ }^{\mathrm{d}}$, tri.astuti@ustjogja.ac.id ${ }^{\mathrm{e}}$
}

${ }^{1}$ Universitas Swadaya Gunung Jati, Cirebon, Indonesia

${ }^{2}$ Universitas Pendidikan Indonesia, Bandung, Indonesia

${ }^{3}$ Universitas Negeri Malang, Malang, Indonesia

${ }^{4}$ Universitas Sarjanawiyata Tamansiswa, Yogyakarta, Indonesia

\begin{abstract}
Mathematical literacy helps one to understand the benefits of using mathematics for everyday life and make the right decisions for a person. Mathematical literacy presents a person's ability to formulate, apply and interpret mathematics in a variety of contexts, including the ability to do mathematical reasoning and use concepts, procedures, and facts to describe, explain or estimate phenomena/events. The purpose of this study was to analyze the validity of Camtasia studio-assisted instructional media in linear programming material and enhancement of analytical literacy capability through the implementation of Camtasia studio-assisted instructional media. This research is development research that is the development of learning media of linear material program supported by Camtasia studio using the model of device development 4-D model consist of four development stage, that is defined, design, develop, and disseminate. Research subjects in learning media trials are XI-1 class students as many as 34 students of academic year 2017/2018 at Vocational High School 1 Cirebon. Camtasia studio-assisted teaching media on linear programming material is very valid, and Implementation of Camtasia studio-assisted learning media developed can improve students' mathematical literacy skills.
\end{abstract}

Keywords: Camtasia Studio, Video, Mathematical Literacy

\section{Introduction}

Mathematical thinking requires an understanding of the exact meaning of the language of mathematics and vocabulary. The success of students solving math problems is based on their ability to translate Indonesian into mathematical languages. The findings reveal the ability of students to read and understand the issues in a story problem most often encountered in students. To uncover students 'difficulties in understanding the story, the level of students' reading ability, and understanding mathematical vocabulary requires particular attention.

Based on the results of interviews with some teachers Vocational High School 1 Cirebon explained that when students solve problems in the form of a story, there are still many students who have difficulty in understanding the meaning of the issue presented. Students are given three questions in the kind of a story and two problems that are ready to be completed. The results of observations and direct interviews conducted with students in two schools showed the 
stout students who did not understand the meaning of the contents of the matter. In the Curriculum 2013, the questions presented are more presented in story form. Problem-solving in the kind of stories of students is expected to practice and think deductively, see the relationship and usefulness of mathematics in everyday life, and can master mathematical skills and strengthen the mastery of mathematical concepts But in real conditions, there are still errors to solve the problem of mathematics.

Problems to interpret a sentence that will be expressed in mathematical issues in the form of mathematical modeling, it occupies a significant space in the mathematics curriculum for the junior level. Mathematical story problems play a role in the daily life of students because the matter put forward real issues that fit with everyday life. Mathematics is a form of mathematical problems that contain aspects of the ability to read, reason, analyze and find solutions, for which students are required to master the skills in solving the math story. Through the story of the teacher can evaluate the student's ability to basic concepts of mathematics that have been studied in the form of a matter of the application of the formula. Sepeng and Sigola illustrate that students have difficulty in reading and understanding problems with mathematical language [1], continued which states The Newman Procedure include reading, comprehension, transformation, process skill, encoding [2]. The method that analyzes the error in the problem of sentences states the obstacles experienced by students in solving the problem of mathematical problems is the problem on language fluency and conceptual understanding in reading and understanding the meaning of a problem.

The learners make mistakes not because they are weak, but because of a strategy error that can be used to solve problems [3, 4]. They conclude that learners do not understand the question and as a result, they are not able to apply appropriate strategies, rules, and concepts to solve the problem. Thus the math teacher should be aware of the problem of reading and counting involving word problems.

One of the problems in solving math problems is a matter of math that uses words or problems (word problems). Bergeson concludes that students in resolving the question of the story are confronted with the issue of words, experiencing cognitive difficulties if surgery is required and the solution procedure contradicts the operation in the underlying structure of the problem. Other factors that make cognitive challenges are the position of the question in the matter of the story, the specific level in words in the subject, the magnitude of numbers, the number of signaling actions of the operations used in the settlement, and the availability of real props.

Attempts to determine the relationship between reading ability and the ability to solve story problems are inconsistent and varied, and there is no significant correlation. Furthermore, the importance of the problem matter lies in the centrality of language in teaching and learning in mathematics. The demand for language literacy in the mathematics curriculum is significant and needs to be developed, as it contributes to the difficulties experienced by students in working on math story problems. Thus the mathematics teacher should be aware of the issue of the importance of language and numeracy which involves the question of mathematical stories.

Based on the observations that the author conducted in Vocational High School 1 Cirebon by spreading the questionnaire data to 20 students of class XII and interviewing math teachers. Getting the first result in the questionnaire data that as many as $68 \%$ of students felt that learning on linear program materials is so abstract that it is difficult for them to keep their attention on the ongoing learning process. This is supported by the results of interviews of researchers to teachers stated that in learning linear program materials to students, in general teachers do not use the media learning. Therefore, the imagination in the management of the direct material program of students of class XII is very less. Lack of supportive literacy ability based on the 
second result of questionnaire data given only $42 \%$ of respondents who dare to ask the teacher if have difficulty in comprehending a sentence. Thus learning needs to be packaged interestingly to motivate students in learning as well as to minimize problems in the learning process.

The learning process needs to be examined wisely, either in learning resources or any way of learning so that learning objectives can be achieved as expected. Learning outcomes are often indicated by learning problems in the learning process of the students, in understanding the material. Based on that it causes teachers to be more creative in delivering the content so that students are more interested and motivated to learn math. One of the learning strategies that can motivate students in learning is by presenting learning media. Teaching media can be understood as anything that can convey or distribute messages from a source in a planned manner, resulting in a conducive learning environment where recipients can perform the learning process efficiently and effectively[5-8].

This multimedia learning can be a substitute for a book that is easy to carry anywhere to learn and expected students could more active learning to understand the subject matter better including solving problems in the form of mathematical concepts. Based on the above background, then the formulation of the problem in this study as follows. (1) Is the Camtasia studio-assisted learning media on linear program material valid ?, (2) Is the implementation of Camtasia studio-assisted teaching media developed to improve the ability of mathematical literacy.

\section{Method}

This research is development research that is a development of learning media linear program material assisted by Camtasia studio. The event of teaching media aims to maximize the role of teaching media in schools that are valid and can improve students' literacy skills. Research and development methods is a research method used to produce a particular product, and test the validity of the product $[9,10]$. The flow of this study using the model of learning device development as suggested 4D model by Thiagarajan are define, design, develop, and disseminate [11].

Learning media that have become assessed feasibility by the validation of experts, i.e., material experts, and media experts. Once validated and the results are valid, instructional media are piloted on students to measure students' measurable literacy improvement. In this study, which became the subject of research in learning media trials are XI-1 class students as many as 34 students academic year 2017/2018 at Vocational High School 1 Cirebon.

The data collection technique uses a questionnaire by providing an expert validation sheet for assessing the feasibility of the media. To measure the improvement of students' mathematical literacy skills using test questions. Data obtained from the implementation of the research then analyzed. The data in the form of expert validation sheet is analyzed by finding the percentage of the entire validator. For the data in the form of test results, the normalized gain test is performed 


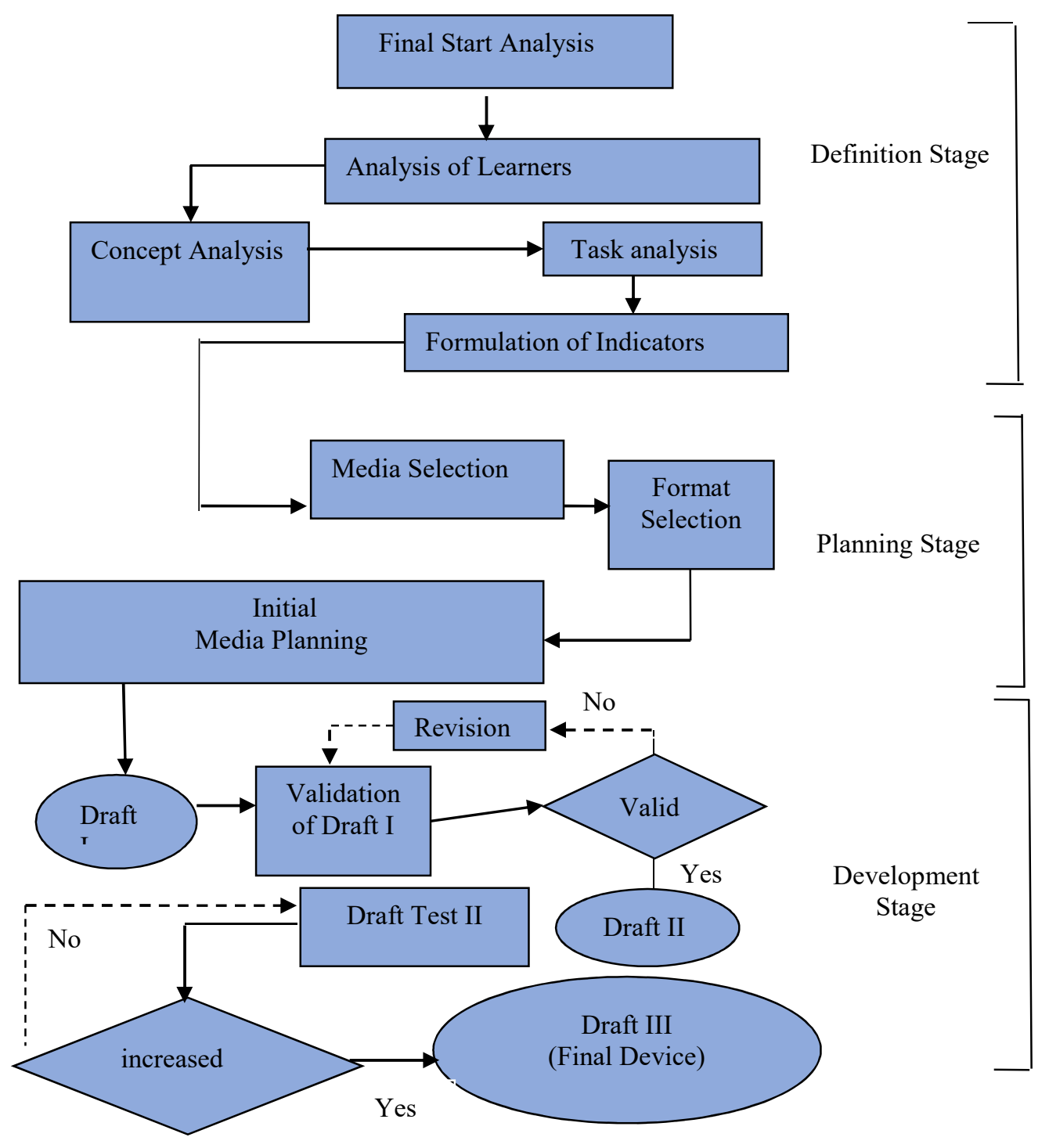

Figure 1. Model of 4-D learning development

\section{Result and Discussion}

Data validation of instructional media from three expert validators is analyzed got the result of an analysis that the learning media criteria are very valid with presentation $91,31 \%$. Validity was seen from each validator expert who assessed where the expert validator one as a material 
expert get a percentage of $95.42 \%$, expert two as a media expert get a percentage of $88.15 \%$ and specialist validator three as a language $89.84 \%$. Thus the results of the three validators are very valid criteria means that the learning media does not require a revision. But there are some inputs from expert one validators that are considered by the author as improving the media for better. Suggestions from validators relate to textual and visual elemental indicators, which are significant enough to fix the media, and some sentences need to be fixed.

The result of learning obstacle analysis shows that the students 'inability to retell the story described in the story, can be proved by the students' ability in speaking and transforming the story to the problem in their language orally. Many of the students have difficulty in telling the oral point of intent. Other evidence on this indicator can be seen in the prerequisite aspect (students cannot identify what is known and asked on the matter). Factors that cause the students' inability to tell the story of the students do not understand the meaning of the question; the students cannot relate the understanding of the language with the familiar situation, the students are not trained in communicating ideas/ideas orally.

The results showed that the ability of mathematical literacy increased with average normalized gain criteria of 0.72 . Medium standardized gain criterion with the details of 18 students with high standards, 12 students with prevailing standards and four students with low rules. The increase was also seen from each indicator of communication; the ability to communicate that applied to the number of questions 1 and 3 obtained a high-value normalized gain value of 0.76 . The second indicator of mathematizing that is changing the problem from the real world to its mathematical form or vice versa applied to problem number 4 got the high value of normalized gain also 0,72 . The third indicator of representation, i.e., presenting a problem applied to problem number 2 obtains a normalized gain value of 0.67 with a medium criterion. The fourth indicator is Using Symbolic, Formal and Technical Language and Operations, the ability to use symbol language, formal language, and technical language; applied to Problem 5 and 6 obtained a normalized gain value of 0.66 medium criterion.

Teaching mathematics is not just a sequence of information, but it needs to review its relevance to the usefulness and interests of students in their lives. By learning math, students are expected to be able to solve problems, find and communicate ideas that appear in the minds of students, and expected students have the ability of mathematical literacy to achieve good results.

The presence of discretion in finding problems indicates that the tendency of students to truly enjoy learning, to stimulate interest and curiosity and the challenge to solve the problems faced become very open and very likely to be realized. In such a way, of course, the purpose of learning that leads to the increase of mathematical literacy students are expected to be able to reach optimally Alternative knowledge as an effort to improve students' mathematical literacy is learning to develop learning media in the form of video Camtasia studio.

The problem used in learning is also not just any problem. The question used should meet the following four characteristics: real, complex, exciting and compelling. The real meaning is that the issue describes the general context and the real problem. Also, the problem should to be complicated to require students to identify the right questions. Not only that, the difficulties presented should not be just a matter of the ordinary story. The issue presented can be a problem that has information overload or something that is not yet known.

As individual studies, they become educated. This idea is at the heart of the third approach, which sees literacy as a broad and focused, focused, and comprehensive educational intervention. By leveraging Dewey and Piaget scholarships, constructivist educators focus on how individual learners, especially children, understand their learning experiences. In the area 
of adult education, some scientists view the personal experience as the primary source of learning.

In line with the results obtained research is "one of the usefulness of learning media can clarify the message so as not too verbalism" $[5,8]$. Learning media is an intermediary in the form of learning resources or physical vehicles that contain visual material in the form of visual and even there are audio that can be used for learners to support learning activities. Software Camtasia become the main ingredient by the author to create an exciting learning media by raising audiovisual to clarify and make students interested in learning mathematics. Computer learning can accommodate students who are slow to receive knowledge because it can provide a more effective climate in a more individualized and non-boring way, Camtasia Studio is an application program packaged for recording, editing, and publishing in creating video presentations on a computer screen.

Although researchers try to be as optimal as possible, still some weaknesses or limitations arise. Gaps or constraints among others, research is only conducted on schools with research samples performed only limited to populations whose characteristics are by school conditions and this study has not considered family, socioeconomic factors, and other psychological factors, which may affect the aspects investigated.

\section{Conclusion}

The term literacy is not only directed to the field of mathematics. Scholarship has a variety of meanings. To find out whether a student has the ability literate or not required indicator that reflects aspects of necessary skills that must be owned to facilitate the teacher in judging.

To improve the ability of mathematical literacy can be applied to various strategies, models, and learning approaches. The policies, models, and methods to be used are linked to the ability of mathematical literacy. A teacher must be good at choosing strategies, models or appropriate approaches so that the knowledge of mathematical literacy can be realized. In addition to the model of a teacher must be able to develop strategies to recognize the understanding of mathematical literacy in students.

Based on the results of data analysis research and discussion it can be concluded as follows, Camtasia studio-assisted learning media on linear programming material is very valid, it is indicated by the average percentage of $91.31 \%$ of the total value of media expert and expert material experts validator. Implementation of Camtasia studio-assisted learning media developed to improve students' mathematical literacy skills, is shown by an average increase in overall students of 0.70 that criteria for a high rise.

Based on the above conclusions, suggestions that can be given by researchers are as follows, Camtasia studio-assisted learning media can be used in the learning process in the classroom to motivate student learning if the infrastructure is met in the school. To further improve the ability of students' mathematical literacy with the implementation of instructional media, should multiply the exercise questions, especially the story that requires a strategy to solve the problem.

\section{References}

[1] P. Sepeng and S. Sigola, "Making Sense of Errors Made by Learners in Mathematical Word Problem Solving," vol. 4, no. 13, pp. 325-334, 2013. 
[2] N. Prakitipong and S. Nakamura, "Analysis of Mathematics Performance of Grade Five Students in Thailand Using Newman Procedure," vol. 9, no. 1, pp. 111-122, 2006.

[3] S. A. Widodo, "ERROR ANALYSIS OF GUARDIANS STUDENT IN UNDERSTANDING THE PROBLEM OF DIVERGENCE," in Proceeding of International Conference On Research, Implementation And Education Of Mathematics And Sciences 2014, 2014, no. May, pp. 18-20.

[4] S. A. Widodo, "Increasing Skills of Student in Junior High School to Problem Solving in Geometry with Guided," vol. 10, pp. 390-395, 2016.

[5] S. A. Widodo, Darhim, and T. Ikhwanudin, "Improving mathematical problem solving skills through visual media Improving mathematical problem solving skills through visual media," J. Phys. Conf. Ser., vol. 948, no. 1, pp. 1-6, 2018.

[6] S. A. Widodo, R. C. I. Prahmana, A. S. Purnami, and Turmudi, "Teaching materials of algebraic equation," J. Phys. Conf. Ser., vol. 943, no. 1, pp. 1-6, 2017.

[7] S. A. Widodo, A. S. Purnami, and R. C. I. Prahmana, "Team accelerated instruction, initials, and problem-solves ability in junior high school," Int. J. Emerg. Math. Educ., vol. 1, no. 2, pp. 193-204, 2017.

[8] S. A. Widodo and Wahyudin, "Selection of Learning Media Mathematics for Junior School Students," Turkish Online J. Educ. Technol., vol. 17, no. 1, pp. 154-160, 2018.

[9] Pardimin and S. A. Widodo, "Development Comic Based Problem Solving in Geometry," Int. Electron. J. Math. Educ., vol. 12, no. 3, pp. 233-241, 2017.

[10] S. A. Widodo, "Development of Teaching Materials Algebraic Equation To Improve Problem Solving," Infin. J., vol. 6, no. 1, p. 59, 2017.

[11] S. Thiagarajan, D. S. Semmel, and M. I. Semmel, Instructional Development for Training Teachers of Exceptional Children: A Sourcebook, no. Mc. Bloomington: Center for Innovation in Teaching the Handicapped, Indiana University, 1974. 